\title{
Statin use and histopathological change in patients with non-alcoholic fatty liver disease: a systematic review and meta-analysis
}

\author{
Pakkapon Rattanachaisit 1,3, Paweena Susantitaphong ${ }^{2,3}$, Kessarin Thanapirom $^{1,3}$, \\ Roongruedee Chaiteerakij 1,3, Piyawat Komolmit ${ }^{1,3}$, Pisit Tangkijvanich ${ }^{4}$, Sombat Treeprasertsuk ${ }^{1,3 *}$
}

\begin{abstract}
Background: Non-alcoholic fatty liver disease (NAFLD) is one of the major causes of chronic liver disease. The primary treatment of NAFLD by statins has not been clearly elucidated.

Objectives: To evaluate the effectiveness of statin use in patients with biopsy-proven NAFLD or non-alcoholic steatohepatitis on the change in liver histology.

Methods: We searched MEDLINE, Scopus, Google Scholar, and the Cochrane Central Register of Controlled Trials for clinical trials and observational studies investigating the effects of statins on histological change regardless of type or dosage from inception to December 2015. Random-effect model meta-analyses were used to compute changes in outcomes of interest. The study protocol was registered in advance with the International Prospective Register of Systematic Reviews (PROSPERO 2016 CRD42016033132).

Results: We identified 6 studies (111 patients), representing 5 cohort studies and 1 randomized controlled clinical trial. There was significant decrease in steatosis grading with a standardized mean difference of -2.580 ( $95 \%$ confidence interval $[\mathrm{CI}]-4.623$ to $-0.536 ; P=0.013)$ and NAFLD activity score standardized mean difference of $-1.488(95 \% \mathrm{CI}-2.506$ to $-0.471 ; P=0.004)$. However, there was no significant change in fibrosis stage $(0.156 ; 95 \% \mathrm{CI}-0.553$ to $0.865 ; P=0.667)$. Conclusions: Statin use can possibly reduce the extent of steatohepatitis but not the stage of fibrosis. Further randomized controlled studies to assess histological evidence with adequate sample size and duration are required in order to establish the role of statin as a primary treatment of NAFLD.
\end{abstract}

Keywords: fatty liver, fatty liver disease, HMG-CoA, hydroxymethylglutaryl-CoA reductase inhibitors, non-alcoholic, statins, steatohepatitis

Non-alcoholic fatty liver disease (NAFLD) is a leading cause of chronic liver disease worldwide. The disease spectrum ranges from fatty liver, non-alcoholic steatohepatitis (NASH), fibrosis, cirrhosis, and hepatocellular carcinoma.
In general, the definition of NAFLD comprises evidence for fatty infiltration in liver tissue either by histology or imaging and known causes of fat accumulation must be excluded, whereas NASH is classified as steatosis and inflammation

*Correspondence to: Sombat Treeprasertsuk, Department of Medicine, Faculty of Medicine, Chulalongkorn University, Bangkok 10330,

Thailand, e-mail: sombat.t@chula.ac.th

'Department of Medicine, Division of Gastroenterology, Faculty of Medicine, Chulalongkorn University, Bangkok 10330, Thailand

2Department of Medicine, Division of Nephrology, Faculty of Medicine, Chulalongkorn University, Bangkok 10330, Thailand

${ }^{3}$ The Thai Red Cross Society, Bangkok 10330, Thailand

${ }^{4}$ Center of Excellence in Hepatitis and Liver Cancer, Department of Biochemistry, Faculty of Medicine, Chulalongkorn University, Bangkok 10330, Thailand

¿ Open Access. ( 2018 Pakkapon Rattanachaisit et al., published by Sciendo. (๔) BY-NC-ND This work is licensed under the Creative Commons Attribution NonCommercial-NoDerivatives 4.0 License. 
with or without fibrosis [1]. Recent meta-analyses suggest that NAFLD is a precursor of type 2 diabetes and metabolic syndrome, and is independently associated with cardiovascular disease $[2,3]$. Dyslipidemia is one of the major metabolic modifiers of the high-risk group for NAFLD [4].

There are scant data of statin effects on liver histology. Despite liver biopsy as the criterion standard for diagnosis and ensuing outcomes, it is limited by the risk of this technique. The Cochrane meta-analysis of statin effect on NAFLD included 2 trials with a high risk of bias and limited numbers of participants. Neither of these trials demonstrated the effect of statins on liver histology [5]. Primary treatment of NASH by statins is not recommended by the practice guidance from the American Association for the Study of Liver Diseases (AASLD) unless there are randomized controlled trials (RCTs) to confirm its histological efficacy [1]. Therefore, the present study aims to review the available evidence for statin use in patients with biopsy-proven NAFLD or NASH regarding the change in liver histology and to summarize the effects by meta-analysis methods.

\section{Methods}

All analyses were based on previously published studies; there was no interaction with patients directly in this analysis; thus, no institutional review board approval or patient consent was required. The study protocol was registered in advance with the International Prospective Register of Systematic Reviews (PROSPERO 2016 CRD42016033132) (available from: http://www.crd.york.ac.uk/PROSPERO/display_record. php?ID=CRD42016033132).

\section{Data sources and searches}

We performed a MEDLINE literature search (inception to December 2015) to identify eligible studies using the Medical Subject Headings search terms "HMG-CoA reductase inhibitor(s)", "statin(s)", "simvastatin", "atorvastatin", "pitavastatin", "rosuvastatin", "lovastatin", "pravastatin", "fluvastatin", "biopsy*", "histology*”, "histopathology", "steatosis", "cirrhosis", "non-alcoholic steatohepatitis (NASH)", "non-alcoholic fatty liver disease (NAFLD)", and free text. Scopus, Google Scholar, and the Cochrane Central Register of Controlled Trials (CENTRAL) were also searched using similar keywords.

\section{Study selection}

Studies included in this meta-analysis were RCTs, observational studies, and nonrandomized clinical trials that investigated the effects of statins on histological change in the entire spectrum of NAFLD patients regardless of type or dosage. The trials had a treatment duration of at least 1 year and followed up with a biopsy. There were no restrictions on language, sample size, or publication type. The titles and abstracts of studies identified in the search were reviewed independently by two authors (PR and KT) and excluded by consensus if studies did not answer the research question of interest. The full text of the articles was retrieved for a comprehensive review and was independently rescreened. In instances of multiple publications from the same investigators and population, the most recent studies were included.

\section{Data extraction and quality assessment}

Data extraction was performed independently by two reviewers (PR and KT). The following data were extracted onto a form: study design, country of origin, year of publication, and sample size, as well as data on statin treatment characteristics including type of medication (if reported) and dose and duration of statin used (if reported). Baseline characteristics such as age and body mass index were also obtained.

We extracted data on the effect of statin therapy as follows: percentage of steatosis, steatosis grading, fibrosis stage, necroinflammatory activity grade, and non-alcoholic fatty liver disease activity score (NAS). Steatosis grading was classified as follows: grade 1 ( $\geq 5 \%$ and $<33 \%$ of hepatocytes affected), grade $2(33 \%-66 \%$ of hepatocytes affected), or grade 3 ( $>66 \%$ of hepatocytes affected). Fibrosis stage and necroinflammatory activity grade were assessed semiquantitatively on a scale of $0-4$ and $0-3$, respectively, as reported by Brunt et al. [6]. The NAS was calculated as the unweighted sum of the scores for steatosis $(0-3)$, lobular inflammation $(0-3)$, and ballooning (0-2), as previously described by Kleiner et al. [7]. Apart from the data on histopathology, data on the effect of statin on blood lipid and lipoproteins and liver enzymes were extracted, including total cholesterol, triglyceride, low-density lipoprotein (LDL), high-density lipoprotein (HDL), aspartate aminotransferase (AST), and alanine transaminase (ALT).

The methodological quality of observational studies was assessed using the Cochrane assessment of bias for nonrandomized studies tool (ROBINS-I) [8]. For the RCTs, the Cochrane Collaboration's tool for assessing risk of bias was used. The use of following strategies was associated with assessing good-quality studies: adequacy of sequence generation; allocation concealment; blinding of investigators, participants, outcome assessors, and data analysts; handling of incomplete outcome data; and selective outcome reporting [9]. Any disagreement was reevaluated with the joint consensus based on original articles. 


\section{Data synthesis and analysis}

We used the random-effects model described by DerSimonian and Laird to analyze mean pre-to-post changes in treatment outcome for a prospective single-arm study (pre-post study or before and after study) [10]. For RCTs, we calculated the mean absolute net changes in the outcome by means of randomeffects model meta-analysis. Where few RCTs were included, the statin arm was pooled together with cohort studies. All pooled estimates are displayed with a $95 \%$ confidence interval (CI). Statistical heterogeneity was evaluated using the $I^{2}$ index and Q-test $P$ value. Either $P^{2}>50 \%$ or $\chi^{2}$ test $P<0.1$ indicates substantial heterogeneity [11]. When heterogeneity was detected, subgroup analysis was performed.

Publication bias was examined using funnel plots and Egger's linear regression method. Funnel plots were constructed if sufficient $(\geq 10)$ eligible trials were available [12]. All analyses were performed using Comprehensive Meta-Analysis (version 2.0; Biostat, available at www.meta-analysis.com).

\section{Results}

\section{Characteristics and quality of the studies}

The initial search identified a total of 534 articles from the electronic databases (MEDLINE, $\mathrm{n}=431$; Scopus, $\mathrm{n}=35$;
Google Scholar, $\mathrm{n}=61$; CENTRAL, $\mathrm{n}=7$ ). Following the exclusion of duplicated data and screening on the basis of titles and abstracts, 505 articles were further dismissed. After intensive assessment of 29 studies, 6 studies fulfilled our criteria and were included in the meta-analysis, including 5 cohort studies [13-17] and 1 RCT [18]. All cohort studies were single-arm studies. Exclusion criteria were as follows: not an NASH patient $(n=6)$ [19-24], no matched biopsy $(n=13)$ [25-37], follow-up time $<1$ year $(\mathrm{n}=2)[38,39]$, and overlapping population $(n=2)[40,41]$. A detailed flow chart showing the selection process is shown in Figure 1.

The characteristics of the included studies are shown in Table 1. The extracted outcomes are as follows: percentage of steatosis, steatosis grading, fibrosis stage, necroinflammatory activity grade, NAS, total cholesterol, triglyceride, LDL, HDL, AST, and ALT. The number of patients and studies included in each analysis is shown in Table 2.

All studies included reported the change in total cholesterol $(n=6)$ and triglyceride $(n=6)$. The main findings and outcomes extracted from each study are shown in Table 3. Treatment duration is mainly 1 year across the selected studies (Table 1).

Quality assessments of each included study are presented in Table 1. The included RCT, the 2009 trial by Nelson et al. [18], had a high risk of bias, according to the Cochrane Collaboration's tool for assessing risk of bias, which identified 2 potential biases, including selection bias and reporting

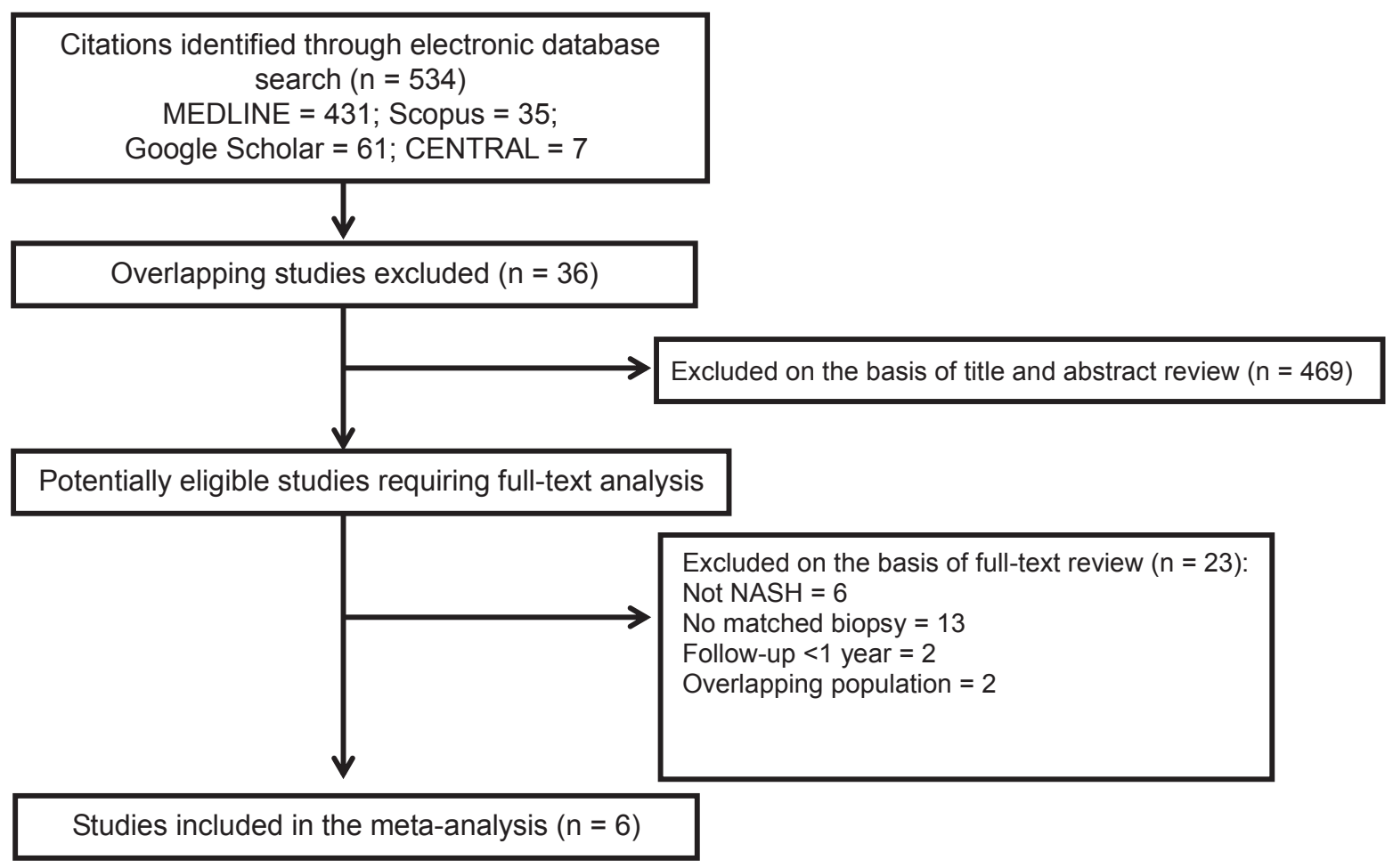

Figure 1. Study selection flow diagram 
Table 1. Characteristics of the studies included in the meta-analysis

\begin{tabular}{|c|c|c|c|c|c|c|c|c|}
\hline Author & $\begin{array}{l}\text { Year } \\
\text { [ref] }\end{array}$ & Country & Study design & Patients, $\mathbf{n}^{+}$ & $\begin{array}{l}\text { Type of statin } \\
(\mathrm{mg} / \mathrm{dL})\end{array}$ & $\begin{array}{l}\text { Follow-up } \\
\text { time (year) }\end{array}$ & $\begin{array}{c}\text { Statin duration } \\
\text { (year) }\end{array}$ & $\begin{array}{l}\text { Study } \\
\text { quality }^{\S}\end{array}$ \\
\hline Nelson et al. & 2009 [18] & USA & $\mathrm{RCT}$ & $10^{\ddagger}$ & Simvastatin (40) & 1 & 1 & Lowll \\
\hline Ekstedt et al. & 2007 [13] & Sweden & $\begin{array}{l}\text { Retrospective } \\
\text { cohort }\end{array}$ & 17 & NA & $10.3-16.3$ & $1-15.9$ & Ser \\
\hline Hyogo et al. & $2011[14]$ & Japan & $\begin{array}{l}\text { Prospective } \\
\text { cohort }\end{array}$ & 13 & Pitavastatin (2) & 1 & 1 & Mod" \\
\hline Nakahara et al. & 2012 [15] & Japan & $\begin{array}{l}\text { Prospective } \\
\text { cohort }\end{array}$ & 9 & Rosuvastatin (2.5) & 2 & 2 & Mod" \\
\hline Hyogo et al. & 2012 [16] & Japan & $\begin{array}{l}\text { Prospective } \\
\text { cohort }\end{array}$ & 42 & Atorvastatin (10) & 1 & 1 & Mod" \\
\hline Kargiotis et al. & 2015 [17] & Greece & $\begin{array}{l}\text { Prospective } \\
\text { cohort }\end{array}$ & 20 & Rosuvastatin (10) & 1 & 1 & Mod" \\
\hline
\end{tabular}

${ }^{\dagger}$ Number of patients in statin treatment arm, ${ }^{\ddagger}$ data from the statin arm. ${ }^{\S}$ Quality assessment using Cochrane Collaboration's tool for assessing risk of bias for RCT and Cochrane assessment of bias for non-randomized studies tool (ROBINS-I). "Risk of bias legend for RCT illustrated in Table 4. "Risk of bias legend for nonrandomized studies illustrated in Table $\mathbf{5}$.

Mod, moderate; NA, not available; RCT, randomized controlled trial; Ser, serious.

Table 2. Summary effects of statins on liver steatosis and fibrosis parameters

\begin{tabular}{|c|c|c|c|c|c|c|}
\hline \multirow{2}{*}{ Outcomes } & \multirow{2}{*}{ Studies, $\mathbf{n}$} & \multirow{2}{*}{ Patients, $\mathbf{n}$} & \multirow{2}{*}{ Standardized mean change $^{\dagger}$} & \multirow{2}{*}{$P$} & \multicolumn{2}{|c|}{ Assessment of heterogeneity } \\
\hline & & & & & $I^{2}$ index, $\%^{*}$ & Q-test, $P^{\ddagger}$ \\
\hline$\%$ of steatosis & 2 & 27 & $-0.580(-1.599,0.439)$ & 0.265 & 93 & $<0.001$ \\
\hline Steatosis grading & 3 & 42 & $-2.580(-4.623,-0.536)$ & 0.013 & 98 & $<0.001$ \\
\hline NAFLD activity score & 4 & 84 & $-1.488(-2.506,-0.471)$ & 0.004 & 96 & $<0.001$ \\
\hline Necroinflammatory activity grade & 2 & 23 & $-0.112(-0.372,0.148)$ & 0.398 & 0 & 0.454 \\
\hline Fibrosis stage & 4 & 49 & $0.156(-0.553,0.865)$ & 0.667 & 92 & $<0.001$ \\
\hline Total cholesterol & 6 & 111 & $-1.540(-2.221,-0.859)$ & $<0.001$ & 93 & $<0.001$ \\
\hline Triglyceride & 6 & 111 & $-0.764(-1.334,-0.195)$ & 0.009 & 94 & $<0.001$ \\
\hline High-density lipoprotein & 4 & 84 & $0.423(-0.070,0.917)$ & 0.093 & 89 & $<0.001$ \\
\hline Low-density lipoprotein & 5 & 94 & $-1.865(-2.416,-1.313)$ & $<0.001$ & 83 & $<0.001$ \\
\hline Alanine transaminase & 5 & 91 & $-0.511(-0.650,-0.373)$ & $<0.001$ & 0 & 0.680 \\
\hline Aspartate aminotransferase & 5 & 91 & $-0.462(-0.599,-0.325)$ & $<0.001$ & 0 & 0.594 \\
\hline
\end{tabular}

Data in parentheses denote $95 \%$ confidence limits. ${ }^{\dagger}$ By random-effects model meta-analysis. ${ }^{\ddagger} \mathrm{A}$ measure of statistical heterogeneity across study results; either $P>50 \%$ or $\chi^{2}$ test $P<0.1$ indicates substantial heterogeneity [11].

NAFLD, non-alcoholic fatty liver disease.

bias (Table 4). The assessment of study quality for included observational studies revealed moderate-to-serious risk of bias according to the Cochrane assessment of bias for nonrandomized studies tool (ROBINS-I) [8]. Detailed assessment is shown in Table 5.

\section{Statins decrease steatosis and steatohepatitis}

As shown in Table 2, the effect of statins on steatosis is demonstrated by the change in percentage of steatosis and steatosis grading. Necroinflammatory activity grade and NAS were used to assess the change in steatohepatitis. There was a significant decrease in steatosis grading (Figure 2) with a standardized mean difference of $-2.580(95 \%$ CI -4.623 to -0.536 ; $P=0.013$ ) and NAS (Figure 3) with a standardized mean difference of $-1.488(95 \% \mathrm{CI}-2.506$ to $-0.471 ; P=0.004)$.

\section{Statins do not change fibrosis stage significantly}

From a meta-analysis of the 4 studies included, there was no significant change in fibrosis stage $(0.156 ; 95 \% \mathrm{CI}-0.553$ to $0.865 ; P=0.67$ ) (Figure 4). 
Table 3. Outcomes and main findings of the studies included in the meta-analysis

\begin{tabular}{|c|c|c|c|c|c|c|c|c|c|c|c|c|}
\hline \multirow[b]{2}{*}{$\begin{array}{l}\text { Author } \\
\text { (year) }\end{array}$} & \multicolumn{11}{|c|}{ Outcomes } & \multirow[b]{2}{*}{ Main findings } \\
\hline & 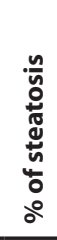 & 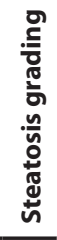 & ñ & 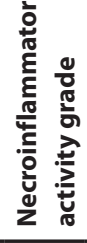 & 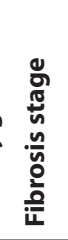 & 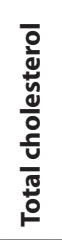 & 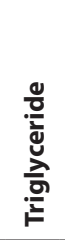 & 모 & $\vec{\Delta}$ & 与 & 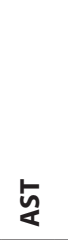 & \\
\hline $\begin{array}{l}\text { Nelson et al. } \\
\text { (2009) [18] }\end{array}$ & Yes & No & No & Yes & Yes & Yes & Yes & No & Yes & Yes & Yes & $\begin{array}{l}\text { - } 26 \% \text { reduction in LDL between simvastatin vs placebo } \\
\text { - No statistically significant improvement in ALT, AST, hepatic steatosis, } \\
\text { necroinflammatory activity, or stage of fibrosis within or between } \\
\text { groups }\end{array}$ \\
\hline $\begin{array}{l}\text { Ekstedt et al. } \\
\text { (2007) [13] }\end{array}$ & Yes & No & No & No & Yes & Yes & Yes & No & No & Yes & Yes & $\begin{array}{l}\text { - Significant reduction in quantitative steatosis in the statin cohort } \\
\text { between baseline and follow-up } \\
\text { - AST/ALT did not differ significantly between the two cohorts }\end{array}$ \\
\hline $\begin{array}{l}\text { Hyogo et al. } \\
\text { (2011) [14] }\end{array}$ & No & Yes & Yes & Yes & Yes & Yes & Yes & Yes & Yes & Yes & Yes & $\begin{array}{l}\text { - Significant decrease in ALT and lipid profiles } \\
\text { - NAS tended to be decreased but statistical significance was not shown } \\
\text { - Fibrosis stage did not change significantly }\end{array}$ \\
\hline $\begin{array}{l}\text { Nakahara et al. } \\
\text { (2012) [15] }\end{array}$ & No & Yes & Yes & No & Yes & Yes & Yes & Yes & Yes & Yes & Yes & $\begin{array}{l}\text { - Mean AST/ALT did not significantly change during the treatment } \\
\text { - NAS and fibrotic stage tended to decrease after the treatment but } \\
\text { statistical significance was not shown }\end{array}$ \\
\hline $\begin{array}{l}\text { Hyogo et al. } \\
\text { (2012) [16] }\end{array}$ & No & No & Yes & No & No & Yes & Yes & Yes & Yes & Yes & Yes & $\begin{array}{l}\text { - Significant decrease in AST and ALT } \\
\text { - Significant improvement in NAS }\end{array}$ \\
\hline $\begin{array}{l}\text { Kargiotis et al. } \\
\text { (2015) [17] }\end{array}$ & No & Yes & Yes & No & No & Yes & Yes & Yes & Yes & No & No & $\begin{array}{l}\text { - Complete resolution of NASH in } 19 \text { of } 20 \text { patients } \\
\text { - AST, ALT, and lipid profiles were normalized by the } 3^{\text {rd }} \text { month of } \\
\text { treatment }\end{array}$ \\
\hline
\end{tabular}

ALT, alanine transaminase; AST aspartate aminotransferase; HDL, high-density lipoprotein; LDL, low-density lipoprotein; NAS, non-alcoholic fatty liver disease activity score; $\mathrm{NASH}$, non-alcoholic steatohepatitis.

Table 4. Risk of bias for the randomized controlled trial by Nelson et al. [18]

\begin{tabular}{ll}
\hline Grade & Bias \\
\hline- & Random sequence generation (selection bias) \\
- & Allocation concealment (selection bias) \\
0 & Blinding of participants and personnel (performance bias) \\
0 & Blinding of outcome assessment (detection bias) \\
\hline & Incomplete outcome data (attrition bias) \\
\hline
\end{tabular}

Black, high grade; gray, moderate grade; white, low grade.

\section{Statins decrease blood lipid and lipoproteins}

There was a significant decrease in the standardized mean difference of total cholesterol $(-1.540,95 \%$ CI -2.221 to -0.859 ; $P<0.001)$, triglyceride $(-0.764,95 \%$ CI -1.334 to -0.195 ; $P=0.009)$, and LDL $(-1.865,95 \% \mathrm{CI}-2.416$ to $-1.313 ; P<0.001)$.

\section{Statins decrease liver enzyme levels}

There was a significant reduction in liver enzyme levels with a standardized mean difference of -0.511 (95\% CI -0.650 to $-0.373 ; P<0.001)$ in AST and $-0.462(95 \% \mathrm{CI}-0.599$ to $-0.325 ; P<0.001)$ in ALT.

\section{Investigations of heterogeneity}

Subgroup analysis was not performed because insufficient studies were included. Significantly different treatment effects were seen between studies; however, as there were only a few studies to classify per subanalysis, it was difficult to interpret any subgroup analysis result.

Funnel plots and Egger's test for the main outcomes of interest were not assessed because $<10$ studies were included and the power of the tests is too low to distinguish chance from genuine asymmetry [12]. 
Table 5. Risk of bias assessment for nonrandomized studies

\begin{tabular}{|c|c|c|c|c|c|}
\hline Domain & Ekstedt et al. [13] & Hyogo et al. [14] & Nakahara et al. [15] & Hyogo et al. [16] & Kargiotis et al. [17] \\
\hline Confounding & Moderate & Moderate & Moderate & Moderate & Moderate \\
\hline Selection & Serious & Low & Low & Low & Low \\
\hline Measurement of interventions & Serious & Low & Low & Low & Low \\
\hline Performance & Low & Low & Low & Low & Low \\
\hline Missing data & Low & Low & Low & Low & Low \\
\hline Measurement of outcomes & Low & Low & Low & Low & Low \\
\hline Reporting & Low & Low & Low & Low & Low \\
\hline Overall & Serious & Moderate & Moderate & Moderate & Moderate \\
\hline
\end{tabular}

\begin{tabular}{|c|c|c|c|c|c|c|c|c|c|}
\hline Study name & \multicolumn{3}{|c|}{ Statistics for each study } & & \multicolumn{5}{|c|}{ Std diff in means and $95 \% \mathrm{Cl}$} \\
\hline & $\begin{array}{l}\text { Std diff } \\
\text { in means }\end{array}$ & $\begin{array}{cc}\text { Lower } & \text { Upper } \\
\text { limit limit }\end{array}$ & $P$ & Total & & & & & \\
\hline Hyogo et al. [14] & -0.450 & $-0.810-0.089$ & 0.015 & 13 & & & & & \\
\hline Nakahara et al. [15] & -0.342 & $-0.767 \quad 0.083$ & 0.115 & 9 & & & & & \\
\hline Karagiotis et al. [17 & ] -7.773 & $-9.322-6.225$ & 0.000 & 20 & & & & & \\
\hline \multirow{3}{*}{$\begin{array}{l}\text { Overall } \\
\left(I^{2} 98 \% ; P 0.013\right)\end{array}$} & -2.580 & $-4.623-0.536$ & 0.013 & 42 & & & & & \\
\hline & & & & & -12.00 & -6.00 & 0.00 & 6.00 & 12.00 \\
\hline & & & & & & avors statin & \multicolumn{3}{|c|}{ Favors no statin } \\
\hline
\end{tabular}

Figure 2. Forest plot displaying the effect of statin on Std diff of steatosis grading. Cl, confidence interval; Std diff, standardized mean difference

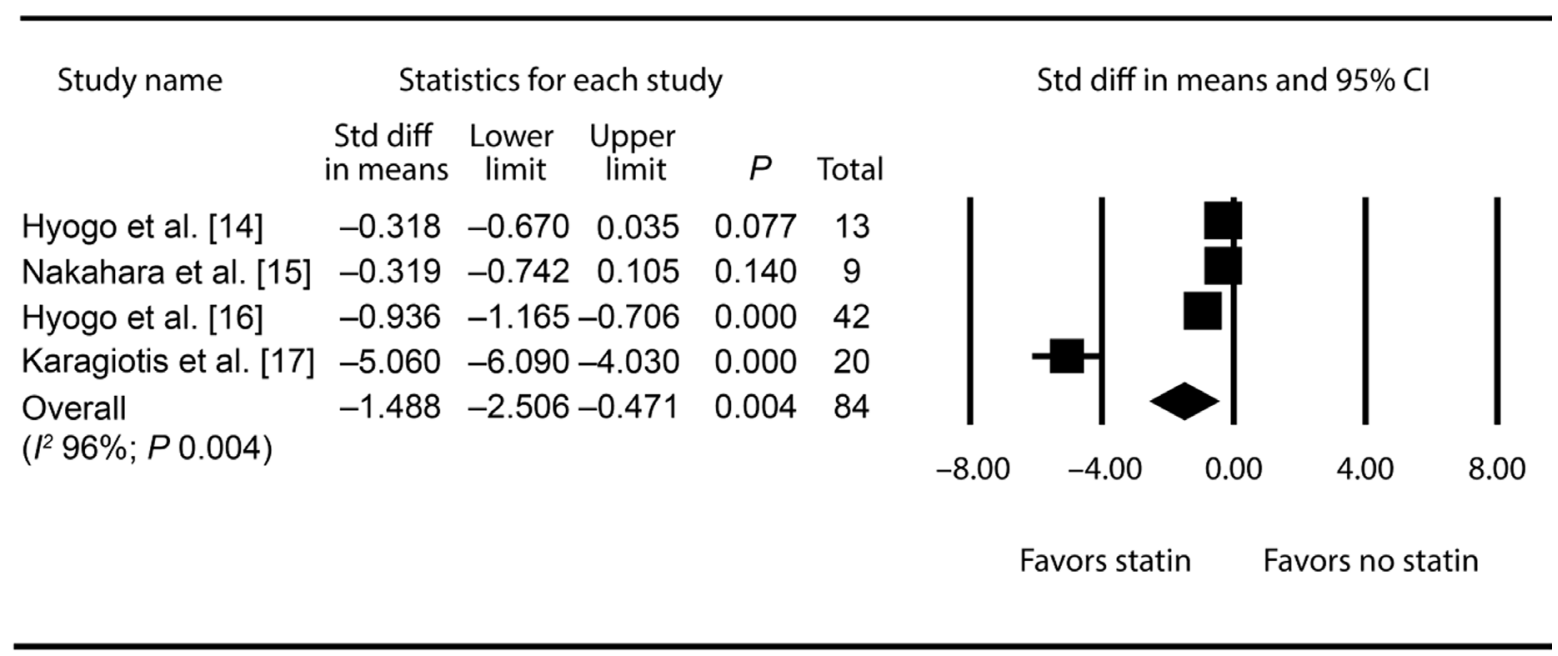

Figure 3. Forest plot displaying the effect of statin on Std diff of NAFLD activity score (NAS). Cl, confidence interval; NAFLD, non-alcoholic fatty liver disease; NAS, non-alcoholic fatty liver disease activity score; Std diff, standardized mean difference 


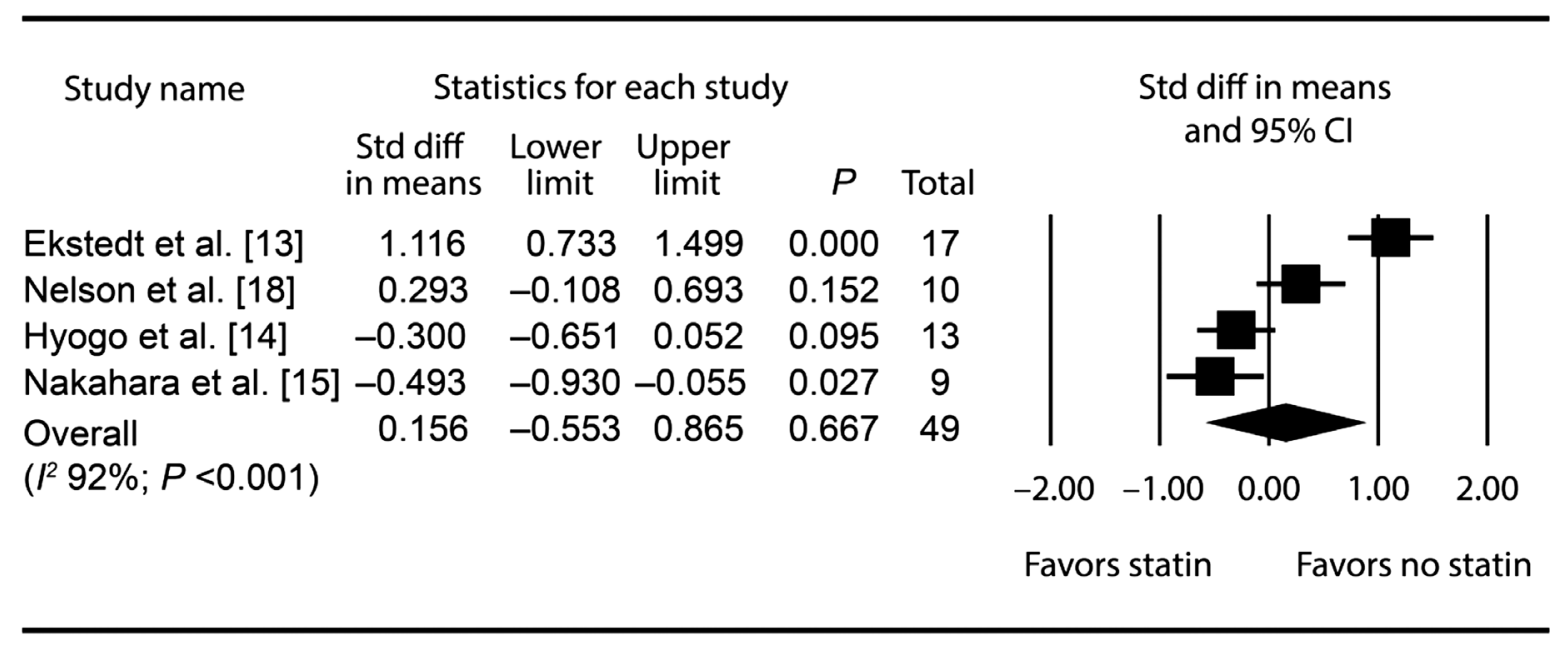

Figure 4. Forest plot displaying the effect of statin on Std diff of fibrosis stage. Cl, confidence interval; Std diff, standardized mean difference

\section{Discussion}

The main finding from this meta-analysis is that statin use can possibly reduce the extent of steatohepatitis but not the stage of fibrosis in NAFLD. By comparing preand posttreatment histological parameters, a significant change was found in markers for steatosis and steatohepatitis, the steatosis grading, and NAS. However, there was an insufficient evidence to support any antifibrotic activity of statins.

Beyond cholesterol-lowering effects by inhibition of the 3-hydroxy-3-methylglutaryl-coenzyme A reductasedependent pathway, statins inhibit cell growth and angiogenesis, and exert anti-inflammatory, proapoptotic, and antifibrotic activities [42-49]. In statin and NASH studies in animal models, prevention of hepatic steatosis and fibrosis was observed, and various mechanisms proposed, including anti-inflammatory, antiapoptotic, and antioxidant effects [50-52].

One of the activities that statins reduced is hepatic lipid infiltration, which was observed in patients treated with atorvastatin. Alterations in the expression of several genes involved in triglyceride and carbohydrate metabolism resulted in reduced plasma, very LDL, and liver triglyceride mass [53].

Our meta-analysis suggests a reduction in the percentage of steatosis and necroinflammatory activity grade, although these trends are not significant. These findings, which are incongruent with the significant reduction in other outcomes, can be attributed to the small sample size and the incomplete outcomes retrieved from the included study (Table 3). The paucity of sample size might have led to a lack of statistical power that must be taken into account when interpreting the results.

Statins are considered to beneficially influence liver fibrosis and portal hypertension by various mechanisms. The current findings include hepatic stellate cell deactivation, reduced migration, reduced collagen synthesis, vasodilation, and hepatic stellate cell senescence [54]. However, our metaanalysis cannot illustrate these effects on fibrosis. The independent antifibrotic effects found for various statins could also be an explanation. Additionally, the short follow-up time of the included study might present only the early stage of fibrotic change. From the meta-analysis, the average rate of fibrosis progression of one stage is more than 7.7 years in patients with NASH and 14.3 years in patients with NAFLD [55].

The heterogeneous findings from the present study may be the result of several factors. First, the pharmacokinetics of each statin varies in metabolism and excretion. Most statin metabolism takes place in liver, while the excretion depends on hydrophobicity. The liver mostly excretes hydrophobic compounds, such as simvastatin, whereas hydrophilic compounds, such as pravastatin, are mainly eliminated through the kidney [56]. In patients with kidney and liver disease, alteration in pharmacokinetics of statins has been observed [57-59]. Cirrhotic patients show an increase in pitavastatin plasma concentration after administration compared with normal controls [59]. Second, patients with NAFLD have alteration in lipid metabolism and steatosis progression caused by polymorphisms. Increases in expression of cytochrome P450 2E1 and polymorphisms in peroxisome proliferator-activated receptors (PPAR) $\alpha$ and $\gamma 2$ have been linked to NAFLD [60]. Thus, the response to each statin treatment may differ in this 
group of patients. The third factor is the response to statin in each patient. Because the cytochrome P450 family is the main metabolic pathway of statin, genetic variation of intracellular cotransporters of the ATP-binding cassette family and enzymes of the cytochrome P450 family or PPAR may impact statin metabolism and response [60]. The variation in LDL-cholesterol reduction response in patients treated with the same dose of the same statin has been observed. These differences might result from single-nucleotide polymorphisms [61].

The safety of a statin in a patient with liver disease is a point of concern when prescribing it to the patients. Statins can cause asymptomatic elevation in ALT and AST, called "transaminitis", and there is a concern of hepatotoxicity in patients with underlying liver disease. In a recent survey, only a half of 937 primary care physicians would prescribe statins to their patients with baseline ALT more than 1.5 times of the upper normal limit [62]. In practice, most people can tolerate statins and rarely suffer from any adverse effects. The incidence of acute liver failure in patients exposed to statins is estimated to be similar to that of the general population $(1: 130,000 \mathrm{vs}$. $1: 114,000)$ [63].

In patients with baseline abnormal liver tests as in patients with NAFLD, the prescription of statins is a challenging practice for physicians who have concerns about liver toxicity. However, the current evidence supports their use by showing a reduction or normalization of liver enzymes and a reduction in the cardiovascular risk in patients with abnormal ALT at baseline $[58,64]$. A post hoc analysis of statin use in an RCT studying the effect of pioglitazone in patients with NASH found that this statin is also safe in patients with prediabetes/ type 2 diabetes mellitus [65].

A post hoc analysis of the Greek Atorvastatin and Coronary Heart Disease Evaluation (GREACE) Study to analyze the liver-related adverse effects of statin treatment in patients with coronary heart disease and liver enzyme elevation showed interesting findings. The frequency of liver-related adverse effects was low in treatment groups both with and without a statin $(1.1 \%$ and $0.4 \%, P=0.2$, respectively), and there was an improvement in liver tests during 3-year follow-up in the statin treatment group [19]. In a randomized, open-label study, which was prospectively performed in patients with elevated LDL, elevated ALT, and no evidence of viral hepatitis or alcohol use, pitavastatin and atorvastatin equally reduced LDL-cholesterol and ALT [66]. An improvement in ALT and AST was also demonstrated in our meta-analysis. Therefore, physicians should not hesitate to use statins in patients with NAFLD and hyperlipidemia.

Statin use is associated with protection from the full spectrum of NAFLD including steatosis and fibrosis [36]. However, only fibrosis is associated with a worse liver outcome. A multicentered longitudinal study demonstrated that regardless of other histological feature, liver fibrosis was the most relevant feature associated with long-term overall mortality, liver transplantation, and liver-related events. The utility of NAS could not provide any long-term prognostic data [67].

Statins are not the key therapy for NASH at present. However, their benefit for cardiovascular disease, which is prevalent in NAFLD populations, should not be overlooked [68].

The recommended treatments according to the 2018 AASLD guidelines are weight reduction, vitamin E, and pioglitazone in non-diabetic adults with biopsy-proven NASH [1]. Despite the established recommendation, there are several ongoing investigations of other drugs such as glucagon-like peptide 1 agonists, statins, pentoxifylline, and obeticholic acid $[36,69]$. One of the key confounders of the included studies is the lack of information regarding body weight change during the treatment with statins.

The present meta-analysis has some limitations, most of which result from the quality of included studies and the limited number of the patients. We found only $1 \mathrm{RCT}$ and 5 observational studies. There was heterogeneity among the meta-analysis results that needs further evaluation for other factors. In addition, the action of statins is complicated, not only their class effect but also the type and dose-specific factors that influence individualized responses. However, similar trends in steatohepatitis reduction were found in most studies.

\section{Conclusions}

The present meta-analysis suggests that statin use can possibly reduce the extent of steatohepatitis but not the stage of fibrosis. Therefore, we encourage physicians to prescribe statins as routine management for NAFLD patients without hesitation, especially for those who have cardiovascular indications for statin use. Further randomized controlled studies assessing histological evidence with adequate size and long duration are required to establish statins as a primary treatment for NAFLD.

\section{Author contributions}

ST proposed the study concept, interpreted the data, and critically edited the manuscript; PR reviewed the literature, extracted the data, conducted the meta-analysis, and drafted the manuscript; PS interpreted the data; KT reviewed the 
literature and extracted data; RC, PK, and PT critically revised the manuscript for important content. All authors approved the final version of the manuscript and take responsibility for the statements made in the published article.

\section{Acknowledgments}

We thank the GI research coordinator Miss Kanokwan Sornsiri for contributing to the data collection. This work has been presented in part at the 26th Annual Conference of the Asian Pacific Association for the Study of the Liver, February 15-19, 2017, Shanghai, China (Rattanachaisit P, Susantitaphong P, Thanapirom K, Chaiteerakij R, Komolmit P, Tangkijvanich P, Treeprasertsuk P. Statin use and histopathological change in non-alcoholic fatty liver disease (NAFLD): meta-analysis [PP1555]. Hepatol Int. 2017; 11(Suppl 1):S929). This study was funded by the Liver Research Unit and an NAFLD research grant to the Division of Gastroenterology, and a research presentation grant from the Department of Medicine, Chulalongkorn University, Bangkok, Thailand.

\section{Conflict of interest}

The authors have each completed and submitted an International Committee of Medical Journal Editors Uniform Disclosure Form for Potential Conflicts of Interest. None of the authors has anything to disclose.

\section{References}

[1] Chalasani N, Younossi Z, Lavine JE, Charlton M, Cusi K, Rinella $\mathrm{M}$, et al. The diagnosis and management of nonalcoholic fatty liver disease: practice guidance from the American Association for the Study of Liver Diseases. Hepatology. 2018; 67:328-57.

[2] Ballestri S, Zona S, Targher G, Romagnoli D, Baldelli E, Nascimbeni F, et al. Nonalcoholic fatty liver disease is associated with an almost twofold increased risk of incident type 2 diabetes and metabolic syndrome. Evidence from a systematic review and meta-analysis. J Gastroenterol Hepatol. 2016; 31:936-44.

[3] Targher G, Byrne CD, Lonardo A, Zoppini G, Barbui C. Non-alcoholic fatty liver disease and risk of incident cardiovascular disease: a meta-analysis. J Hepatol. 2016; 65:589-600.

[4] Lonardo A, Bellentani S, Argo CK, Ballestri S, Byrne CD, Caldwell $\mathrm{SH}$, et al. Epidemiological modifiers of non-alcoholic fatty liver disease: Focus on high-risk groups. Dig Liver Dis. 2015; 47:997-1006.

[5] Eslami L, Merat S, Malekzadeh R, Nasseri-Moghaddam S, Aramin $\mathrm{H}$. Statins for non-alcoholic fatty liver disease and non-alcoholic steatohepatitis. Cochrane Database Syst Rev. 2013:CD008623. doi: 10.1002/14651858.CD008623.pub2.

[6] Brunt EM, Janney CG, Di Bisceglie AM, Neuschwander-Tetri BA, Bacon BR. Nonalcoholic steatohepatitis: a proposal for grading and staging the histological lesions. Am J Gastroenterol. 1999; 94:2467-74.

[7] Kleiner DE, Brunt EM, Van Natta M, Behling C, Contos MJ, Cummings OW, et al. Design and validation of a histological scoring system for nonalcoholic fatty liver disease. Hepatology. 2005; 41:1313-21.

[8] Sterne JA, Hernán MA, Reeves BC, Savović J, Berkman ND, Viswanathan M, et al. ROBINS-I: a tool for assessing risk of bias in non-randomised studies of interventions. BMJ. 2016; 355:i4919. doi: 10.1136/bmj.i4919

[9] Schuünemann H BJ, Guyatt G, Oxman A, editors. GRADE handbook for grading quality of evidence and strength of recommendations [Internet]. The GRADE Working Group; 2013 [updated October 2013; cited 2017 June 02]. Available from: http:// gdt.guidelinedevelopment.org/app/handbook/handbook.html

[10] DerSimonian R, Laird N. Meta-analysis in clinical trials. Control Clin Trials. 1986; 7:177-88

[11] Huedo-Medina TB, Sánchez-Meca J, Marín-Martínez F, Botella J. Assessing heterogeneity in meta-analysis: Q statistic or I2 index? Psychol Methods. 2006; 11:193-206.

[12] Egger M, Davey Smith G, Schneider M, Minder C. Bias in meta-analysis detected by a simple, graphical test. BMJ. 1997; 315:629-34.

[13] Ekstedt M, Franzén LE, Mathiesen UL, Holmqvist M, Bodemar $\mathrm{G}$, Kechagias S. Statins in non-alcoholic fatty liver disease and chronically elevated liver enzymes: A histopathological follow-up study. J Hepatol. 2007; 47:135-41.

[14] Hyogo H, Ikegami T, Tokushige K, Hashimoto E, Inui K, Matsuzaki $\mathrm{Y}$, et al. Efficacy of pitavastatin for the treatment of non-alcoholic steatohepatitis with dyslipidemia: An open-label, pilot study. Hepatol Res. 2011; 41:1057-65.

[15] Nakahara T, Hyogo H, Kimura Y, Ishitobi T, Arihiro K, Aikata H, et al. Efficacy of rosuvastatin for the treatment of nonalcoholic steatohepatitis with dyslipidemia: an open-label, pilot study. Hepatol Res. 2012; 42:1065-72.

[16] Hyogo H, Yamagishi S, Maeda S, Kimura Y, Ishitobi T, Chayama K. Atorvastatin improves disease activity of nonalcoholic steatohepatitis partly through its tumour necrosis factor- $\alpha$-lowering property. Dig Liver Dis. 2012; 44:492-6.

[17] Kargiotis K, Athyros VG, Giouleme O, Katsiki N, Katsiki E, Anagnostis $\mathrm{P}$, et al. Resolution of non-alcoholic steatohepatitis by rosuvastatin monotherapy in patients with metabolic syndrome. World J Gastroenterol. 2015; 21:7860-8.

[18] Nelson A, Torres DM, Morgan AE, Fincke C, Harrison SA. A pilot study using simvastatin in the treatment of nonalcoholic steatohepatitis: a randomized placebo-controlled trial. J Clin Gastroenterol. 2009; 43:990-4.

[19] Athyros VG, Tziomalos K, Gossios TD, Griva T, Anagnostis P, Kargiotis K, et al.; GREACE Study Collaborative Group. Safety and efficacy of long-term statin treatment for cardiovascular events in patients with coronary heart disease and abnormal liver tests in the Greek Atorvastatin and Coronary Heart Disease Evaluation (GREACE) Study: a post-hoc analysis. Lancet. 2010; 376:1916-22. 
[20] Simon TG, King LY, Zheng H, Chung RT. Statin use is associated with a reduced risk of fibrosis progression in chronic hepatitis $\mathrm{C}$. J Hepatol. 2015; 62:18-23.

[21] Henderson LM, Patel S, Giordano TP, Green L, El-Serag HB. Statin therapy and serum transaminases among a cohort of HCV-infected veterans. Dig Dis Sci. 2010; 55:190-5.

[22] Kumar S, Grace ND, Qamar AA. Statin use in patients with cirrhosis: a retrospective cohort study. Dig Dis Sci. 2014; 59: 1958-65.

[23] Butt AA, Yan P, Bonilla H, Abou-Samra AB, Shaikh OS, Simon TG et al. Effect of addition of statins to antiviral therapy in hepatitis $\mathrm{C}$ virus-infected persons: results from ERCHIVES. Hepatology. 2015; 62:365-74.

[24] Yang YH, Chen WC, Tsan YT, Chen MJ, Shih WT, Tsai YH, et al Statin use and the risk of cirrhosis development in patients with hepatitis C virus infection. J Hepatol. 2015; 63:1111-7.

[25] Ábel T, Fehér J, Dinya E, Eldin MG, Kovács A. Safety and efficacy of combined ezetimibe/simvastatin treatment and simvastatin monotherapy in patients with non-alcoholic fatty liver disease. Med Sci Monit. 2009; 15:MS6-11.

[26] Lewis JH, Mortensen ME, Zweig S, Fusco MJ, Medoff JR, Belder $\mathrm{R}$, et al.; Pravastatin in Chronic Liver Disease Study Investigators. Efficacy and safety of high-dose pravastatin in hypercholesterolemic patients with well-compensated chronic liver disease: Results of a prospective, randomized, double-blind, placebo-controlled, multicenter trial. Hepatology. 2007; 46:1453-63.

[27] Gomez-Domínguez E, Gisbert JP, Moreno-Monteagudo JA, García-Buey L, Moreno-Otero R. A pilot study of atorvastatin treatment in dyslipemid, non-alcoholic fatty liver patients. Aliment Pharmacol Ther. 2006; 23:1643-7.

[28] Kiyici M, Gulten M, Gurel S, Nak SG, Dolar E, Savci G, et al. Ursodeoxycholic acid and atorvastatin in the treatment of nonalcoholic steatohepatitis. Can J Gastroenterol. 2003; 17:713-8.

[29] Athyros VG, Mikhailidis DP, Didangelos TP, Giouleme OI, Liberopoulos EN, Karagiannis A, et al. Effect of multifactorial treatment on non-alcoholic fatty liver disease in metabolic syndrome: a randomised study. Curr Med Res Opin. 2006; 22:873-83.

[30] Samy W, Hassanian MA. Paraoxonase-1 activity, malondialdehyde and glutathione peroxidase in non-alcoholic fatty liver disease and the effect of atorvastatin. Arab J Gastroenterol. 2011 12:80-5.

[31] Antonopoulos S, Mikros S, Mylonopoulou M, Kokkoris S, Giannoulis G. Rosuvastatin as a novel treatment of non-alcoholic fatty liver disease in hyperlipidemic patients. Atherosclerosis. 2006; 184:233-4.

[32] Riley P, Sudarshi D, Johal M, Benedict A, Panteli J, Crook M, O'Donohue J. Weight loss, dietary advice and statin therapy in non-alcoholic fatty liver disease: a retrospective study. Int J Clin Pract. 2008; 62:374-81

[33] Foster T, Budoff MJ, Saab S, Ahmadi N, Gordon C, Guerci AD. Atorvastatin and antioxidants for the treatment of nonalcoholic fatty liver disease: the St Francis Heart Study randomized clinical trial. Am J Gastroenterol. 2011; 106:71-7.

[34] Oni ET, Sinha P, Karim A, Martin SS, Blaha MJ, Agatston AS, et al. Statin use is not associated with presence of and severity of nonalcoholic fatty liver disease. Arch Med Res. 2014; 45:52-7.

[35] Avins AL, Manos MM, Ackerson L, Zhao W, Murphy R, Levin TR, et al. Hepatic effects of lovastatin exposure in patients with liver disease: a retrospective cohort study. Drug safety. 2008 31:325-34.

[36] Dongiovanni P, Petta S, Mannisto V, Mancina RM, Pipitone R, Karja V, et al. Statin use and non-alcoholic steatohepatitis in at risk individuals. J Hepatol. 2015; 63:705-12.

[37] Mihaila RG, Nedelcu L, Fratila O, Rezi EC, Domnariu C, Deac M. Effects of lovastatin and pentoxyphyllin in nonalcoholic steatohepatitis. Hepatogastroenterology. 2009; 56:1117-21.

[38] Rallidis LS, Drakoulis CK, Parasi AS. Pravastatin in patients with nonalcoholic steatohepatitis: results of a pilot study. Atherosclerosis. 2004; 174:193-6.

[39] Georgescu EF, Georgescu M. Therapeutic options in non-alcoholic steatohepatitis (NASH). Are all agents alike? Results of a preliminary study. J Gastrointestin Liver Dis. 2007; 16:39-46.

[40] Kimura Y, Hyogo H, Yamagishi S, Takeuchi M, Ishitobi T, Nabeshima Y, et al. Atorvastatin decreases serum levels of advanced glycation endproducts (AGEs) in nonalcoholic steatohepatitis (NASH) patients with dyslipidemia: clinical usefulness of AGEs as a biomarker for the attenuation of NASH. J Gastroenterol. 2010; 45:750-7.

[41] Hyogo H, Tazuma S, Arihiro K, Iwamoto K, Nabeshima Y, Inoue $\mathrm{M}$, et al. Efficacy of atorvastatin for the treatment of nonalcoholic steatohepatitis with dyslipidemia. Metabolism. 2008; 57:1711-8.

[42] Iwaisako K, Brenner DA, Kisseleva T. What's new in liver fibrosis? The origin of myofibroblasts in liver fibrosis. J Gastroenterol Hepatol. 2012; 27(Suppl 2):65-8.

[43] Kisseleva T, Brenner DA. Mechanisms of fibrogenesis. Exp Biol Med. 2008; 233:109-22.

[44] Kuoppala J, Lamminpää A, Pukkala E. Statins and cancer: a systematic review and meta-analysis. Eur J Cancer. 2008; 44:2122-32.

[45] Rao S, Porter DC, Chen X, Herliczek T, Lowe M, Keyomars K. Lovastatin-mediated $\mathrm{G}_{1}$ arrest is through inhibition of the proteasome, independent of hydroxymethyl glutaryl-CoA reductase. Proc Natl Acad Sci U S A. 1999; 96:7797-802.

[46] Schuppan D, Afdhal NH. Liver cirrhosis. Lancet. 2008; 371:838-51.

[47] Sun H-Y, Singh N. Antimicrobial and immunomodulatory attributes of statins: relevance in solid-organ transplant recipients. Clin Infect Dis. 2009; 48:745-55.

[48] Wu J, Wong W-W, Khosravi F, Minden MD, Penn LZ. Blocking the Raf/MEK/ERK pathway sensitizes acute myelogenous leukemia cells to lovastatin-induced apoptosis. Cancer Res. 2004; 64:6461-8.

[49] Simon TG, Butt AA. Lipid dysregulation in hepatitis $C$ virus, and impact of statin therapy upon clinical outcomes. World J Gastroenterol. 2015; 21:8293-303.

[50] Okada Y, Yamaguchi K, Nakajima T, Nishikawa T, Jo M, Mitsumoto $\mathrm{Y}$, et al. Rosuvastatin ameliorates high-fat and high-cholesterol diet-induced nonalcoholic steatohepatitis in rats. Liver Int. 2013; 33:301-11.

[51] Van Rooyen DM, Gan LT, Yeh MM, Haigh WG, Larter CZ, Ioannou $\mathrm{G}$, et al. Pharmacological cholesterol lowering reverses fibrotic NASH in obese, diabetic mice with metabolic syndrome. J Hepatol. 2013; 59:144-52.

[52] Wang W, Zhao C, Zhou J, Zhen Z, Wang Y, Shen C. Simvastatin ameliorates liver fibrosis via mediating nitric oxide synthase in rats with non-alcoholic steatohepatitis-related liver fibrosis. PLoS One. 2013; 8:e76538. doi: 10.1371/journal.pone.0076538

[53] Pramfalk C, Parini P, Gustafsson U, Sahlin S, Eriksson M. Effects of high-dose statin on the human hepatic expression of genes involved 
in carbohydrate and triglyceride metabolism. J Intern Med. 2011; 269:333-9.

[54] Trebicka J, Schierwagen R. Statins, Rho GTPases and KLF2: new mechanistic insight into liver fibrosis and portal hypertension. Gut. 2015; 64:1349-50.

[55] Singh S, Allen AM, Wang Z, Prokop LJ, Murad MH, Loomba R. Fibrosis progression in nonalcoholic fatty liver vs nonalcoholic steatohepatitis: a systematic review and meta-analysis of pairedbiopsy studies. Clin Gastroenterol Hepatol. 2015; 13:643-54.

[56] Gazzerro P, Proto MC, Gangemi G, Malfitano AM, Ciaglia E, Pisanti S, et al. Pharmacological actions of statins: a critical appraisal in the management of cancer. Pharmacol Rev. 2012; 64:102-46.

[57] Lins RL, Matthys KE, Verpooten GA, Peeters PC, Dratwa M, Stolear J-C, et al. Pharmacokinetics of atorvastatin and its metabolites after single and multiple dosing in hypercholesterolaemic haemodialysis patients. Nephrol Dial Transplant. 2003; 18:967-76.

[58] Bologa R, Levine D, Parker T, Gordon B, Lanto A, Cheigh J, et al. Pharmacokinetics of rosuvastatin in patients with end-stage kidney disease undergoing peritoneal dialysis. Clin Nephrol. 2009; 72:437-41.

[59] Hui CK, Cheung BM, Lau GK. Pharmacokinetics of pitavastatin in subjects with Child-Pugh A and B cirrhosis. Br J Clin Pharmacol. 2005; 59:291-7.

[60] Pastori D, Polimeni L, Baratta F, Pani A, Del Ben M, Angelico F. The efficacy and safety of statins for the treatment of non-alcoholic fatty liver disease. Dig Liver Dis. 2015; 47:4-11.

[61] Postmus I, Trompet S, Deshmukh HA, Barnes MR, Li X, Warren $\mathrm{HR}$, et al. Pharmacogenetic meta-analysis of genome-wide association studies of LDL cholesterol response to statins. Nat Commun. 2014; 5:5068. doi: 10.1038/ncomms6068

[62] Rzouq FS, Volk ML, Hatoum HH, Talluri SK, Mummadi RR, Sood GK. Hepatotoxicity fears contribute to underutilization of statin medications by primary care physicians. Am J Med Sci. 2010; 340:89-93.

[63] Onofrei MD, Butler KL, Fuke DC, Miller HB. Safety of statin therapy in patients with preexisting liver disease. Pharmacotherapy. 2008; 28:522-9.

[64] Imprialos KP, Stavropoulos K, Doumas M, Skalkou A, Zografou I, Athyros VG. The potential role of statins in treating liver disease. Expert Rev Gastroenterol Hepatol. 2018; 12:331-9.

[65] Bril F, Portillo Sanchez P, Lomonaco R, Orsak B, Hecht J, Tio F, et al. Liver safety of statins in prediabetes or T2DM and nonalcoholic steatohepatitis: post-hoc analysis of a randomized trial. J Clin Endocrinol Metab. 2017; 102:2950-61.

[66] Han KH, Rha SW, Kang H-J, Bae J-W, Choi B-J, Choi S-Y, et al. Evaluation of short-term safety and efficacy of HMG-CoA reductase inhibitors in hypercholesterolemic patients with elevated serum alanine transaminase concentrations: PITCH study (PITavastatin versus atorvastatin to evaluate the effect on patients with hypercholesterolemia and mild to moderate hepatic damage). J Clin Lipidol. 2012; 6:340-51.

[67] Angulo P, Kleiner DE, Dam-Larsen S, Adams LA, Bjornsson ES, Charatcharoenwitthaya P, et al. Liver fibrosis, but no other histologic features, is associated with long-term outcomes of patients with nonalcoholic fatty liver disease. Gastroenterology. 2015; 149:389-97.

[68] Athyros VG, Tziomalos K, Katsiki N, Doumas M, Karagiannis A, Mikhailidis DP. Cardiovascular risk across the histological spectrum and the clinical manifestations of non-alcoholic fatty liver disease: An update. World J Gastroenterol. 2015; 21:6820-34.

[69] Singh S, Khera R, Allen AM, Murad MH, Loomba R. Comparative effectiveness of pharmacological interventions for nonalcoholic steatohepatitis: A systematic review and network meta-analysis. Hepatology. 2015; 62:1417-32. 